\title{
Biliary lipids, faecal steroids, and liver function in patients with chronic active hepatitis and primary biliary cirrhosis: significance of hepatic orcein-stained complexes
}

\author{
Y A KESÄNIEMI, T A MIETTINEN, AND M P SALASPURO \\ From the Second Department of Medicine, University of Helsinki, Finland
}

SUMMARY Biliary lipids, faecal steroids, and serum bile acids were studied in patients with chronic active hepatitis and primary biliary cirrhosis. The results were correlated with excretory and parenchymal liver function tests and with the presence or absence of orcein-positive copperprotein complexes in histological liver specimens. In general, faecal bile acids, but not neutral and total sterols, correlated negatively with the percentage of biliary cholic acid, serum cholesterol, and serum bile acids and positively with the percentage of biliary deoxycholic acid. In orcein-positive subjects-indicative of long-standing cholestasis - the bile was undersaturated with cholesterol, biliary deoxycholic acid was subnormal, cholic acid correspondingly increased, and serum cholesterol and bile acids were raised. Only the patients with marked impairment of both excretory and parenchymal liver functions had a decreased output of neutral sterols, bile acids, and total steroids, and, thus, low bile acid and cholesterol synthesis. The findings indicate that mild disturbances in parenchymal liver function infrequently cause major changes in cholesterol metabolism, while abnormalities in secretory liver function-in orcein-positive subjects especially-are frequently associated with proportionate changes in parameters of cholesterol metabolism.

Patients with liver disease exhibit an almost complete lack of biliary and plasma deoxycholic acid, ${ }^{1-3}$ raised plasma bile acids, ${ }^{45}$ a decrease in cholic acid pool size,$^{67}$ and a diminution in the hepatic clearance of labelled bile acids. ${ }^{89}$ Biliary cholesterol secretion is reduced more than the secretion of bile acids and phospholipids, ${ }^{10}$ and micellar solubilisation of intestinal lipids and sterols can be markedly reduced." Faecal bile acids and neutral sterols of cholesterol origin are decreased in patients with severe chronic liver disease, while urinary bile acids are constantly, but never greatly, increased, ${ }^{12}$ indicating that the production of cholesterol and its conversion to bile acids is decreased.

The abnormalities of biliary lipids in liver diseases have been mainly reported in alcoholic cirrhosis and factors affecting different aspects of sterol metabolism are poorly understood. In the present study the biliary lipids, faecal steroids, and serum bile acids were

Received for publication 21 January 1981 studied in patients with chronic active hepatitis and primary biliary cirrhosis. The results have been correlated with each other, routine liver function tests and histochemical orcein-staining of liver biopsies. Orcein-positive copper-protein complexes $^{13}$ have been found in severe chronic cholestatic states. ${ }^{14}{ }^{15}$ Some preliminary results of the investigation have been presented earlier. ${ }^{16}$

\section{Methods}

\section{PATIENTS}

The series included nine patients with primary biliary cirrhosis and 24 patients with chronic active hepatitis. In addition, eighteen non-affected first-degree relatives of these patients served as controls.

The diagnosis of primary biliary cirrhosis and chronic active hepatitis was based on the accepted histological, immunological, and clinical findings. ${ }^{17-21}$ Radiological and/or ERCP (endoscopic retrograde cholangiography) studies had been performed in most 
of the patients to exclude extrahepatic cholestasis. The control subjects were studied clinically, immunologically, and also by the hepatic needle biopsy when indicated by abnormal laboratory findings. ${ }^{22}$ Only the ones without any evidence of chronic active hepatitis or primary biliary cirrhosis were included. Gallbladder status was not routinely checked in the controls. All the patients and controls were hepatitis $B$ antigen negative. The duration of the symptoms was more than one year in every case. Histological features of cirrhosis were found in three patients. None of the subjects had ever had clinical signs or history of encephalopathy, melaena, haematemesis, or ascites.

The patients with chronic active hepatitis and primary biliary cirrhosis were subgrouped according to the presence or absence of orcein-positive copperprotein complexes ${ }^{13}$ in the histological liver specimens. The orcein-positivity was present in six out of 24 cases with chronic active hepatitis and in five out of nine cases with primary biliary cirrhosis.

\section{PROCEDURES}

All the patients and controls were hospitalised and placed on a low cholesterol $(125 \mathrm{mg} / 2400 \mathrm{kcal})$ solidfood diet, containing $100 \mathrm{~g}$ of fat (equal amounts of lard and soy bean oil) per $1600 \mathrm{kcal}$. Unabsorbable $\mathrm{Cr}_{2} \mathrm{O}_{3}$ and beta-sitosterol, $600 \mathrm{mg}$ of each divided into three daily doses, were given so that corrections could be made respectively for faecal flow and degradation of cholesterol during intestinal transit. ${ }^{23}{ }^{24}$ After the patients had been on the diet, $\mathrm{Cr}_{2} \mathrm{O}_{3}$ and betasitosterol for five to seven days, two to three day faecal collections were made. After the stool had been collected, the jejunum was intubated and duodenal bile was aspirated after a 12 hour fast, using cholecystokinin to provoke gallbladder contraction.

\section{ANALYTICAL METHODS}

The routine methods of our hospital laboratory were used to estimate serum concentrations of albumin, ${ }^{25}$ alanine aminotransferase ${ }^{26}$ plasma prothrombin, ${ }^{27}$ alkaline phosphatase ${ }^{26}$ leucine aminopeptidase, ${ }^{28}$ gamma-glutamyl-transpeptidase, ${ }^{29}$ bilirubin, ${ }^{30}$ cholesterol,,$^{31}$ and triglycerides..$^{32}$ Transport maximum for bromsulphophthalein was determined according to Wheeler et al. ${ }^{33}$ Serum fasting bile acids were analysed enzymatically. ${ }^{34}$ Faecal fat was measured according to the method of van de Kamer et al. ${ }^{35}$ Chromic oxide $\left(\mathrm{Cr}_{2} \mathrm{O}_{3}\right)$ was determined as reported by Bolin et al. ${ }^{36}$ Cholesterol and bile acids of the duodenal bile, and faecal bile acids and neutral steroids were measured by gas liquid chromatography, ${ }^{37}{ }^{38}$ except that the thin layer chromatography step was omitted in the measurement of bile acids and biliary cholesterol. Biliary phospholipids were measured according to the method of Bartlett. ${ }^{39}$

\section{CLINICS}

A summary of the clinical parameters of patient series is shown in Table 1. The clinical picture of orceinpositive cases was very much the same as in our earlier publication ${ }^{15}$ - that is, characterised by cholestasis: a marked rise in serum alkaline phosphatase, leucine aminopeptidase, gamma-glutamyl-transpeptidase, and greatly impaired transport maximum for bromsulphophthalein. However, serum bilirubin was only moderately increased and only a few patients were clearly jaundiced. Parenchymal liver function indicated by serum albumin and plasma prothrombin showed variable impairment with no consistent difference between the orcein-positive and orceinnegative patients.

\section{SERUM LIPIDS}

Serum cholesterol was within the control limits in

Table 1 Clinical data on control subjects and patients with chronic liver disease (mean $\pm S E$ )

\begin{tabular}{|c|c|c|c|c|c|c|c|c|c|c|c|c|}
\hline Group & $\begin{array}{l}\text { Cases } \\
\text { (no.) }\end{array}$ & $\begin{array}{l}\text { Sex } \\
\text { ratio } \\
M / F\end{array}$ & $\begin{array}{l}\text { Age } \\
\text { (yr) }\end{array}$ & $\begin{array}{l}\text { Weight } \\
(k g)\end{array}$ & $\begin{array}{l}\text { Album } \\
(\mathrm{g} / \mathrm{l}) \\
(38-51)\end{array}$ & $\begin{array}{l}P+P \\
(\%) \\
(80-120)\end{array}$ & $\begin{array}{l}\text { Alat } \\
(U / l) \\
(8-45)\end{array}$ & $\begin{array}{l}\text { Afos } \\
(U / l) \\
(60-240)\end{array}$ & $\begin{array}{l}L A P \\
(U / l) \\
(18-48)\end{array}$ & $\begin{array}{l}\gamma-G T \\
(U / l) \\
(6-28)\end{array}$ & $\begin{array}{l}\text { Bilir. } \\
(\mu \mathrm{mol} / \mathrm{l}) \\
(2-20)\end{array}$ & $\begin{array}{l}B S P-T m^{*} \\
(m g / m i n) \\
(8 \cdot 9-12 \cdot 1)\end{array}$ \\
\hline Controls & 18 & $9 / 9$ & $38 \cdot 6 \pm 2 \cdot 5$ & $74 \cdot 2 \pm 3 \cdot 5$ & $39 \pm 0.9$ & - & $42 \pm 6$ & $147 \pm 13$ & - & - & $11 \pm 1$ & $10 \cdot 5 \pm 0 \cdot 8$ \\
\hline $\mathrm{CAH}$ & $24(1)$ & $8 / 16$ & $42 \cdot 8 \pm 3 \cdot 5$ & $66 \cdot 7 \pm 3 \cdot 5$ & $38 \pm 0 \cdot 7$ & $76 \cdot 6 \pm 3 \cdot 5$ & $143 \pm 52$ & $394 \pm 72+$ & $88 \pm 16$ & $80 \pm 25$ & $13 \pm 1 \cdot 8$ & $4 \cdot 3 \pm 0.4+$ \\
\hline ORC+ & $6(1)$ & $2 / 4$ & $51 \cdot 0 \pm 7 \cdot 8$ & $65 \cdot 5 \pm 6 \cdot 1$ & $36 \pm 1 \cdot 48$ & $85 \cdot 5 \pm 5 \cdot 5$ & $86 \pm 19$ & $933 \pm 1778$ & $193 \pm 38 \S$ & $215 \pm 758$ & $18 \pm 6$ & $3 \cdot 3 \pm 0 \cdot 8$ \\
\hline ORC- & $18(0)$ & $6 / 12$ & $40 \pm 3 \cdot 8$ & $67 \cdot 1 \pm 4 \cdot 3$ & $40 \pm 0 \cdot 7$ & $73 \cdot 6 \pm 4 \cdot 1$ & $159 \pm 66$ & $244 \pm 22$ & $53 \pm 6$ & $35 \pm 9$ & $11 \pm 1$ & $4 \cdot 5 \pm 0 \cdot 4$ \\
\hline PBC & $9(2)$ & $1 / 8$ & $50 \cdot 8 \pm 3 \cdot 7$ & $59 \cdot 4 \pm 4 \cdot 3$ & $36 \pm 1 \cdot 5$ & $86 \cdot 6 \pm 5 \cdot 9$ & $102 \pm 30^{\dagger}$ & $1127 \pm 402+\ddagger$ & $199 \pm 56 \ddagger$ & $148 \pm 42$ & $21 \pm 7$ & $3 \cdot 1 \pm 0 \cdot 5^{+}$ \\
\hline ORC + & $5(2)$ & $1 / 4$ & $51 \cdot 6 \pm 4 \cdot 1$ & $63 \cdot 0 \pm 6 \cdot 5$ & $33 \pm 1 \cdot 58$ & $91 \cdot 2 \pm 8 \cdot 7$ & $141 \pm 49$ & $1735 \pm 6068$ & $274 \pm 89$ & $213 \pm 62$ & $32 \pm 11$ & $2 \cdot 2 \pm 0.9$ \\
\hline ORC- & $4(0)$ & $0 / 4$ & $49 \cdot 8 \pm 7 \cdot 3$ & $55 \cdot 0 \pm 5 \cdot 3$ & $40 \pm 1 \cdot 0$ & $80 \cdot 8 \pm 7 \cdot 8$ & $53 \pm 11$ & $366 \pm 99$ & $105 \pm 21$ & $67 \pm 17$ & $7 \pm 0.9$ & $4 \cdot 1 \pm 0 \cdot 5$ \\
\hline $\mathrm{ORC}+(\mathrm{CAH}+\mathrm{PBC})$ & $11(3)$ & $3 / 8$ & $51 \cdot 3 \pm 4 \cdot 4$ & $64 \cdot 4 \pm 4 \cdot 2$ & $34 \pm 1 \cdot 1 \S$ & $88 \cdot 1 \pm 4 \cdot 8 \S$ & $114 \pm 26$ & $1334 \pm 3268$ & $230 \pm 45 \S$ & $214 \pm 47 \S$ & $24 \pm 6 \S$ & $2 \cdot 7 \pm 0 \cdot 5 \S$ \\
\hline $\mathrm{ORC}-(\mathrm{CAH}+\mathrm{PBC})$ & $22(0)$ & $6 / 16$ & $41 \cdot 8 \pm 3 \cdot 8$ & $64 \cdot 9 \pm 3 \cdot 8$ & $40 \pm 0 \cdot 6$ & $74 \cdot 9 \pm 3 \cdot 6$ & $139 \pm 55$ & $266 \pm 26$ & $63 \pm 7$ & $41 \pm 8$ & $10 \pm 1$ & $4 \cdot 5 \pm 0 \cdot 3$ \\
\hline
\end{tabular}

CAH: chronic active hepatitis. PBC: primary biliary cirrhosis. ORC+: orcein-positive material found in liver biopsies; ORC-: orcein positivity absent in liver biopsies. Figures in parentheses indicate the number of patients with histological features of cirrhosis in the liver biopsy specimens: ${ }^{*}$ Album: serum albumin. $\mathrm{P}+\mathrm{P}$ : plasma prothrombin (Owren). Alat: serum alanine aminotransferase. Afos: serum alkaline phosphatase. LAP: serum leucine aminopeptidase. $\gamma$-GT: gammaglutamyl-transpeptidase. Bilir.: serum bilirubin. BSP-Tm: bromosulphophthalein transport maximum. The normal ranges of laboratory data are given in parentheses. +Statistically significant difference $(P<0.05$ or less) from controls; ¥statistically significant difference $(P<0.05$ or less) between chronic active hepatitis and primary biliary cirrhosis; $\$$ statistically significant difference ( $P<0 \cdot 05$ or less) from orcein-negative cases. M: male. F: female. 
Table 2 Serum and faecal lipids in controls and patients with liver disease (mean $\pm S E$ )

\begin{tabular}{|c|c|c|c|c|c|c|c|c|}
\hline \multirow[t]{2}{*}{ Group } & \multirow{2}{*}{$\begin{array}{l}\text { Cases } \\
\text { (no.) }\end{array}$} & \multicolumn{3}{|l|}{ Serum lipids } & \multicolumn{3}{|c|}{ Faecal steroids $(\mathrm{mg} / \mathrm{kg} /$ day $)$} & \multirow{2}{*}{$\begin{array}{l}\text { Faecal fat } \\
\text { (g/day) }\end{array}$} \\
\hline & & $\begin{array}{l}\text { Cholesterol } \\
(\mathrm{mmcl} / \mathrm{l})\end{array}$ & $\begin{array}{l}\text { Triglycerides } \\
(\mathrm{mmcl} / \mathrm{l})\end{array}$ & $\begin{array}{l}\text { Bile acids } \\
(\mu \mathrm{g} / \mathrm{ml})\end{array}$ & Neutral sterols & Bile acids & Total steroids & \\
\hline Controls & 17 & $6 \cdot 6 \pm 0 \cdot 3$ & $1 \cdot 6 \pm 0 \cdot 2$ & - & $8 \cdot 2 \pm 0 \cdot 8$ & $4 \cdot 7 \pm 0 \cdot 5$ & $13 \cdot 3 \pm 1 \cdot 2$ & $3 \cdot 4 \pm 0 \cdot 3$ \\
\hline $\mathrm{CAH}$ & 24 & $6 \cdot 0 \pm 0 \cdot 2$ & $1 \cdot 1 \pm 0 \cdot 1$ & $2 \cdot 7 \pm 1 \cdot 0$ & $9 \cdot 4 \pm 0 \cdot 6$ & $3 \cdot 3 \pm 0 \cdot 4^{*}$ & $12 \cdot 7 \pm 0 \cdot 7$ & $3 \cdot 9 \pm 0 \cdot 5$ \\
\hline $\mathrm{ORC}+$ & 6 & $7 \cdot 4 \pm 0 \cdot 4 \ddagger$ & $1 \cdot 5 \pm 0 \cdot 3$ & $4 \cdot 3 \pm 1 \cdot 68$ & $9 \cdot 0 \pm 1 \cdot 5$ & $3 \cdot 1 \pm 0 \cdot 9$ & $12 \cdot 1 \pm 1 \cdot 7$ & $6 \cdot 2 \pm 1 \cdot 6$ \\
\hline ORC- & 18 & $5 \cdot 5 \pm 0 \cdot 2$ & $1 \cdot 0 \pm 0 \cdot 1$ & $2 \cdot 0 \pm 1 \cdot 1$ & $9 \cdot 5 \pm 0 \cdot 7$ & $3 \cdot 4 \pm 0 \cdot 4$ & $13 \cdot 0 \pm 0 \cdot 8$ & $3 \cdot 1 \pm 0 \cdot 3$ \\
\hline PBC & 9 & $9 \cdot 9 \pm 1 \cdot 9^{*+}$ & $1 \cdot 4 \pm 0 \cdot 2$ & $9 \cdot 3 \pm 4 \cdot 7$ & $10 \cdot 9 \pm 2 \cdot 0$ & $3 \cdot 1 \pm 0 \cdot 5^{*}$ & $14 \cdot 1 \pm 2 \cdot 3$ & $6 \cdot 1 \pm 1 \cdot 4$ \\
\hline ORC+ & 5 & $12 \cdot 3 \pm 3 \cdot 2$ & $1 \cdot 4 \pm 0 \cdot 3$ & $16 \cdot 3 \pm 7 \cdot 4 \S$ & $9 \cdot 2 \pm 2 \cdot 3$ & $2 \cdot 6 \pm 0 \cdot 6^{*}$ & $11 \cdot 7 \pm 2 \cdot 9$ & $8 \cdot 7 \pm 1 \cdot 6^{*} \ddagger$ \\
\hline ORC- & 4 & $6 \cdot 9 \pm 0 \cdot 5$ & $1 \cdot 5 \pm 0 \cdot 5$ & $0 \cdot 7 \pm 0 \cdot 1$ & $13 \cdot 2 \pm 3 \cdot 4$ & $3 \cdot 8 \pm 0 \cdot 5$ & $17 \cdot 0 \pm 3 \cdot 7$ & $2 \cdot 8 \pm 0 \cdot 4$ \\
\hline $\mathrm{ORC}+(\mathrm{CAH}+\mathrm{PBC})$ & 11 & $9 \cdot 6 \pm 1 \cdot 6 \ddagger$ & $1 \cdot 4 \pm 0 \cdot 2$ & $9 \cdot 7 \pm 3 \cdot 8 \S$ & $9 \cdot 1 \pm 1 \cdot 3$ & $2 \cdot 8 \pm 0 \cdot 5^{*}$ & $11 \cdot 5 \pm 1 \cdot 5$ & $7 \cdot 3 \pm 1 \cdot 1^{*} \ddagger$ \\
\hline $\mathrm{ORC}-(\mathrm{CAH}+\mathrm{PBC})$ & 22 & $5 \cdot 8 \pm 0 \cdot 2$ & $1 \cdot 1 \pm 0 \cdot 1$ & $1 \cdot 8 \pm 0 \cdot 9$ & $10 \cdot 2 \pm 0 \cdot 8$ & $3 \cdot 5 \pm 0 \cdot 3^{*}$ & $13 \cdot 7 \pm 0 \cdot 9$ & $3 \cdot 1 \pm 0 \cdot 2$ \\
\hline
\end{tabular}

Abbreviations as in Table 1.

${ }^{*}$ Statistically significant difference $(p<0 \cdot 05$ or less) from controls.

+ Statistically significant difference $(P<0 \cdot 05$ or less) between chronic active hepatitis and primary biliary cirrhosis.

$¥$ Statistically significant difference $(P<0 \cdot 05$ or less) from orcein-negative patients.

$\$$ Statistically significant difference $(\mathbf{P}<0.05$ or less) from orcein-negative patients, when calculated as logarithms.

chronic active hepatitis and clearly raised in primary biliary cirrhosis (Table 2), even though several cases with the latter disorder had no hypercholesterolaemia. In general, the serum cholesterol level was higher in the orcein-positive than orcein-negative subjects. Serum triglycerides were not consistently affected in either chronic active hepatitis or primary biliary cirrhosis. Serum fasting bile acids were similar in both disorders, but they were higher in the orcein-positive than orcein-negative patients in both primary biliary cirrhosis and chronic active hepatitis.

\section{BILIARY LIPID COMPOSITION}

Biliary lipid composition was normal in the patients with CAH and PBC (Table 3). However, the molar percentage of cholesterol was low and that of bile acids high in the orcein-positive patients. When the molar percentages of the whole material were plotted

Table 3 Molar percentages of biliary lipids in controls and patients with liver diseases (mean $\pm S E$ )

\begin{tabular}{lccll}
\hline Group & $\begin{array}{c}\text { Cases } \\
\text { (no.) }\end{array}$ & Cholesterol & Bile acids & Phospholipids \\
\hline Control & 18 & $7 \cdot 5 \pm 0 \cdot 69$ & $67 \cdot 4 \pm 3 \cdot 1$ & $25 \cdot 2 \pm 2 \cdot 8$ \\
CAH & 24 & $7 \cdot 3 \pm 0 \cdot 9$ & $71 \cdot 7 \pm 1 \cdot 7$ & $21 \cdot 0 \pm 1 \cdot 2$ \\
ORC+ & 6 & $5 \cdot 2 \pm 0 \cdot 6^{*}$ & $73 \cdot 7 \pm 2 \cdot 5$ & $21 \cdot 1 \pm 2 \cdot 3$ \\
ORC- & 18 & $8 \cdot 0 \pm 1 \cdot 1$ & $71 \cdot 0 \pm 2 \cdot 2$ & $21 \cdot 0 \pm 1 \cdot 4$ \\
PBC & 9 & $7 \cdot 8 \pm 1 \cdot 7$ & $71 \cdot 1 \pm 3 \cdot 2$ & $21 \cdot 0 \pm 1 \cdot 6$ \\
ORC+ & 5 & $5 \cdot 0 \pm 1 \cdot 1$ & $76 \cdot 4 \pm 2 \cdot 7^{*}$ & $18 \cdot 6 \pm 1 \cdot 8$ \\
ORC- & 4 & $11 \cdot 4 \pm 2 \cdot 9$ & $64 \cdot 5 \pm 4 \cdot 7$ & $24 \cdot 1 \pm 2 \cdot 2$ \\
ORC+ & & & & \\
(CAH+PBC) & 11 & $5 \cdot 1 \pm 0 \cdot 6^{*}$ & $74 \cdot 9 \pm 1 \cdot 8^{*}$ & $20 \cdot 0 \pm 1 \cdot 5$ \\
ORC- & & $8 \cdot 6 \pm 1 \cdot 0$ & $69 \cdot 8 \pm 2 \cdot 0$ & $21 \cdot 6 \pm 1 \cdot 3$ \\
(CAH+PBC) & 22 & & & \\
\hline
\end{tabular}

Abbreviations as in Table 1 .

${ }^{*}$ Statistically significant difference $(\mathrm{P}<0.05$ or less $)$ from controls or from $\mathrm{ORC}-(\mathrm{CAH}+\mathrm{PBC})$ against the liver function tests of Table 1 the only significant correlation $(r=-0.29 ; \mathrm{p}<0.05 ; \mathrm{n}=50)$ was found between the biliary cholesterol percentage and the serum bilirubin level.

\section{BILIARY BILE ACIDS}

The relative amount of biliary deoxycholic acid was subnormal in chronic active hepatitis and especially in primary biliary cirrhosis (Table 4). Cholic acid was correspondingly increased, while the amount of chenodeoxycholate was unchanged. The changes were most marked in the orcein-positive cases, in primary biliary cirrhosis in particular. The percentage of cholic acid correlated inversely with those of deoxycholic acid $(r=-0.70 ; \mathrm{P}<0.001 ; \mathrm{n}=51)$ and chenodeoxycholic acid $(r=-0 \cdot 44 ; \mathrm{p}<0.001 ; \mathrm{n}=51)$,

Table 4 Relative distribution percentage of biliary bile acids in controls and in patients with liver diseases (mean $\pm S E$ )

\begin{tabular}{lcccc}
\hline $\begin{array}{l}\text { Group } \\
\end{array}$ & $\begin{array}{l}\text { Cases } \\
\text { (no.) }\end{array}$ & Cholic acid & $\begin{array}{l}\text { Deoxycholic } \\
\text { acid }\end{array}$ & $\begin{array}{l}\text { Chenodeoxy- } \\
\text { cholic acid }\end{array}$ \\
\hline Control & 18 & $44 \cdot 1 \pm 1 \cdot 5$ & $21 \cdot 5 \pm 2 \cdot 4$ & $34 \cdot 4 \pm 1 \cdot 9$ \\
CAH & 24 & $51 \cdot 3 \pm 2 \cdot 7^{*}$ & $11 \cdot 5 \pm 2 \cdot 6^{*}$ & $38 \cdot 1 \pm 2 \cdot 0$ \\
$\quad$ ORC+ & 6 & $61 \cdot 5 \pm 6 \cdot 0^{+}$ & $2 \cdot 3 \pm 1 \cdot 3^{\dagger}$ & $36 \cdot 2 \pm 5 \cdot 3$ \\
ORC- & 18 & $47 \cdot 8 \pm 2 \cdot 6$ & $14 \cdot 5 \pm 3 \cdot 2$ & $38 \cdot 8 \pm 2 \cdot 1$ \\
PBC & 9 & $59 \cdot 0 \pm 3 \cdot 8^{*}$ & $5 \cdot 8 \pm 2 \cdot 0^{*}$ & $35 \cdot 2 \pm 3 \cdot 0$ \\
ORC+ & 5 & $65 \cdot 8 \pm 5 \cdot 0^{+}$ & $1 \cdot 2 \pm 0 \cdot 7^{\dagger}$ & $33 \cdot 0 \pm 4 \cdot 7$ \\
ORC- & 4 & $50 \cdot 0 \pm 2 \cdot 5$ & $11 \cdot 5 \pm 2 \cdot 1$ & $38 \cdot 0 \pm 3 \cdot 5$ \\
$\begin{array}{l}\text { ORC+ } \\
\text { (CAH+PBC) }\end{array}$ & 11 & $63 \cdot 5 \pm 3 \cdot 8^{*}$ & $1 \cdot 8 \pm 0 \cdot 8^{*}$ & $34 \cdot 7 \pm 3 \cdot 4$ \\
$\begin{array}{l}\text { ORC- } \\
\text { (CAH+PBC) }\end{array}$ & 22 & $48 \cdot 3 \pm 2 \cdot 2^{+}$ & $13 \cdot 9 \pm 2 \cdot 6^{*+}$ & $38 \cdot 6 \pm 1 \cdot 8$ \\
\hline
\end{tabular}

Abbreviations as in Table 1.

*Statistically significant difference ( $P<0$-05 or less) from controls.

+ Statistically significant difference ( $P<0.05$ or less) between orcein-positive and orcein-negative patients. 


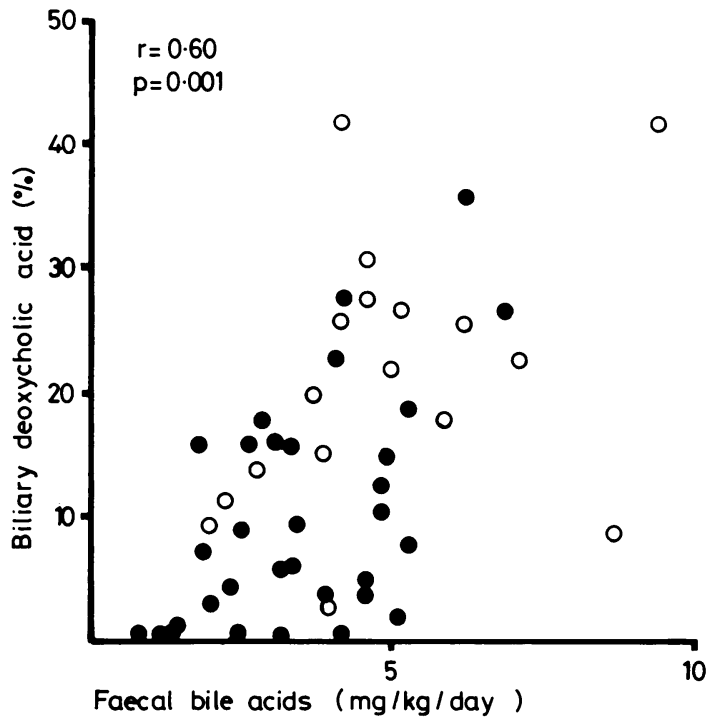

Figure The correlation between the relative percentage of biliary deoxycholic acid and the daily output of faecal bile acids in controls $(\bigcirc)$ and in patients with liver disease $(\bullet)$.

the respective correlation between the two dihydroxy bile acids being less significant $(r=-0.33 ; \mathrm{p}<0.05$; $\mathrm{n}=51$ ). The percentage of biliary cholic acid was positively associated with serum alkaline phosphatase, leucine aminopeptidase, gamma-glutamyl transpeptidase, bilirubin, cholesterol, and fasting bile acids and negatively with serum albumin and the transport maximum of bromosulphophthalein. On the other hand, the dihydroxy bile acids, deoxycholate in particular, correlated negatively with those tests.

FAECAL FAT AND STEROIDS

An increased faecal fat $(7 \mathrm{~g} /$ day $)$ was found in four orcein-positive patients only, one with chronic active hepatitis and three with primary biliary cirrhosis. However, the mean faecal fat was higher in the orcein-positive patients, in the cirrhosis patients in particular, than in orcein-negative patients or controls (Table 2). The mean faecal bile acid output was lower in patients with these disorders and, especially in the orcein-positive patients, than in the controls. Faecal bile acids were not associated with faecal fat or the liver function tests but they correlated positively with the percentage of biliary deoxycholate (Figure), and negatively with the percentage of biliary cholic acid $(r=-0.52 ; \mathrm{P}<0.001 ; \mathrm{n}=50)$, with serum bile acids $(r=-0.39 ; \mathrm{P}<0.05 ; \mathrm{n}=32)$, and with serum cholesterol $(r=-0 \cdot 35 ; \mathrm{p}<0 \cdot 05 ; \mathrm{n}=32)$.

In contrast with bile acids, the faecal excretion of neutral and total sterols was similar in all the patient groups and the controls. However, if abnormal alkaline phosphatase and $\mathrm{P}+\mathrm{P}$ (prothrombin + proconvertin) were used to separate subgroups according to excretory and parenchymal liver function (Table 5) the patients with impairment of both excretory and parenchymal function had decreased faecal neutral and acidic steroids indicative of low bile acid and cholesterol synthesis. In primary biliary cirrhosis the total steroid values (faecal bile acids + neutral steroids of cholesterol origin) were not correlated with any of the liver function tests or serum cholesterol. In orcein-negative chronic active hepatitis patients the total steroid output was negatively correlated with serum cholesterol $(r=-0.50 ; \mathrm{P}<0.05 ; \mathrm{n}=17)$ and alkaline phosphatase $(r=-0.61 ; \quad \mathrm{P}<0.01 ; \mathrm{n}=18)$, but not with the parenchymal liver function tests.

Table 5 Serum, biliary, and faecal lipids in liver patients separated into four subgroups according to excretory and parenchymal liver function (mean $\pm S E$ )

\begin{tabular}{|c|c|c|c|c|}
\hline \multirow[t]{2}{*}{ Parameter } & $A$ & $B$ & $C$ & $D$ \\
\hline & $\begin{array}{l}A F O S- \\
P+P- \\
n=5\end{array}$ & $\begin{array}{l}A F O S- \\
P+P+ \\
n=5\end{array}$ & $\begin{array}{l}A F O S+ \\
P+P- \\
n=16\end{array}$ & $\begin{array}{l}A F O S+ \\
P+P+ \\
n=7\end{array}$ \\
\hline Serum cholesterol & $5 \cdot 4 \pm 0 \cdot 5$ & $5 \cdot 5 \pm 0 \cdot 3^{+}$ & $8 \cdot 7 \pm 1 \cdot 2^{*}$ & $5 \cdot 9 \pm 0 \cdot 4^{+}$ \\
\hline Serum bile acids & $0 \cdot 9 \pm 0 \cdot 4$ & $0 \cdot 7 \pm 0 \cdot 1$ & $6 \cdot 8 \pm 2 \cdot 8$ & $4 \cdot 1 \pm 2 \cdot 7$ \\
\hline Biliary cholic acid $(\%)$ & $38 \cdot 2 \pm 2 \cdot 2$ & $54 \cdot 0 \pm 2 \cdot 8^{*}$ & $57 \cdot 8 \pm 3 \cdot 1^{*}$ & $53 \cdot 6 \pm 5 \cdot 9^{*}$ \\
\hline Biliary deoxycholic acid (\%) & $22 \cdot 8 \pm 4 \cdot 5$ & $9 \cdot 8 \pm 3 \cdot 5$ & $6 \cdot 1 \pm 1 \cdot 9^{*}$ & $6 \cdot 7 \pm 2 \cdot 6^{*}$ \\
\hline Biliary chenodeoxycholic acid (\% & $39 \cdot() \pm 3 \cdot 0$ & $36 \cdot 2 \pm 2 \cdot 0$ & $36 \cdot 1 \pm 2 \cdot 6$ & $39 \cdot 7 \pm 4 \cdot 7$ \\
\hline Faecal neutral sterols $(\mathrm{mg} / \mathrm{kg} / \mathrm{day}$ & $10 \cdot 8 \pm 1 \cdot 3$ & $12 \cdot 8 \pm 3 \cdot 0$ & $9 \cdot 4 \pm 0 \cdot 9$ & $7 \cdot 8 \pm 0 \cdot 6$ \\
\hline Faecal bile acids ( $\mathrm{mg} / \mathrm{kg} /$ day) & $5 \cdot 1 \pm 0 \cdot 6$ & $3 \cdot 4 \pm 0 \cdot 6$ & $3 \cdot 1 \pm 0 \cdot 4^{*}$ & $2 \cdot 2 \pm 0 \cdot 5^{*}$ \\
\hline Total faecal steroids $(\mathrm{mg} / \mathrm{kg} /$ day & $15 \cdot 9 \pm 1 \cdot 3$ & $16 \cdot 3 \pm 3 \cdot 0$ & $12 \cdot 6 \pm 1 \cdot 1$ & $10 \cdot 0 \pm 0 \cdot 9^{*}$ \\
\hline
\end{tabular}

Impairment in excretory liver function was evaluated by serum alkaline phosphatase (AFOS) and that of parenchymal liver function by plasma prothrombin $(\mathrm{P}+\mathrm{P})$. AFOS $-:<244 \mathrm{U} / \mathrm{l}$. AFOS $+=>244 \mathrm{U} / \mathrm{l}$. $\mathrm{P}+\mathrm{P}-=>75$. $\mathrm{P}+\mathrm{P}+=\leq 75$

${ }^{*}$ Statistically significant difference $(\mathrm{P}<0 \cdot 05$ or less) from group $\mathrm{A}$

†Statistically significant difference $(\mathrm{P}<0.05$ or less) from group $\mathrm{C}$.

\section{Discussion}

Analysis of biliary lipid composition has revealed that in patients with severe alcoholic liver cirrhosis the cholesterol saturation is subnormal. ${ }^{10}$ This is associated with a decrease in the secretion rates of all the three biliary lipids, cholesterol, bile acids, and phospholipids. ${ }^{40}$ In less severe forms of alcoholic cirrhosis, however, these disturbances in biliary lipid metabolism have not been found..$^{41}$ In the present study the mean biliary lipid composition of the patients with chronic active hepatitis and primary biliary cirrhosis was within the control limits, despite clear-cut abnormalities in the liver functions tests. However, the severity of the diseases varied markedly and the tests of the secretory function were affected more consistently than those of the parenchymal cell function (Table 1), not only in primary biliary 
cirrhosis but in chronic active hepatitis, too. Further subgrouping according to the presence of orceinpositive material in the liver biopsies separated from both groups of disorder the patients whose secretory liver function tests were most abnormal. This subgrouping, however, separated inconsistently the patients with poor parenchymal cell function. Even though the molar percentage of biliary lipids was not correlated with the liver function tests the finding on the association of the low molar percentage of biliary cholesterol with the orcein positivity indicates that in chronic active hepatitis and primary biliary cirrhosis the bile does not become undersaturated for cholesterol until in the advanced stage of impaired secretory dysfunction.

A decrease in the relative amount of biliary deoxycholic acid and an increase in that of cholic acid characterise the bile acid pattern of cholestatic liver diseases. ${ }^{1-3}$ Impaired parenchymal cell function reduces bile acid synthesis, especially that of cholic acid, resulting in a relative increase in chenodeoxycholic acid. ${ }^{67}$ These observations are confirmed in the present study for both primary biliary cirrhosis and chronic active hepatitis, for orcein-positive subjects in particular. The inconsistent change in biliary chenodeoxycholic acid indicates, however, that the parenchymal cell function was relatively well preserved. This is in accordance with the recent finding that the synthesis and pool size of chenodeoxycholic acid remain unabated in the patients with primary biliary cirrhosis. ${ }^{42} \mathrm{~A}$ negative correlation between the percentages of cholic and chenodeoxycholic acid could be a sign of impaired parenchymal function, though the tests of the parenchymal cell function correlated poorly with the percentage distributions of biliary bile acids. In contrast, the surprisingly strong correlation of the biliary bile acid percentage distribution with the serum bile acid and cholesterol levels and with other tests of cholestasis suggests that the changes in biliary bile acids are related to cholestasis.

Absence of steatorrhoea in the present series does not necessarily mean that the biliary secretion of bile acids was sufficient to maintain the intestinal bile acid level above the critical micellar concentration during fat digestion. Fatty acids are absorbed along the small intestine to some extent without micellar solubilisation..$^{434}$ Thus, in patients with liver disease and severe disturbance of micellar formation, faecal fat can be modestly increased only. ${ }^{12}$ In fact, low biliary bile acid secretion associated with normal bile acid absorption could explain low faecal bile acids in the present series. The low faecal bile acid output and the low biliary cholesterol saturation, in orcein-positive subjects in particular, actually suggest that the secretion of biliary lipids had decreased and that the output of biliary cholesterol had decreased even more than that of bile acids. Two possible mechanisms can then be visualised for normal faecal neutral sterols in the present series. First, reduced biliary bile acid secretion impaired micellar solubilisation of lipids. In contrast with fatty acids, micellar solubilisation is a prerequisite for cholesterol absorption..$^{456}$ Thus, bile acid deficiency reduced absorption of both dietary and endogenous cholesterol, particularly in the orcein-positive subjects, so that faecal output of neutral sterols remained normal. Secondly, cholesterol secretion via the intestinal mucosa may be increased. This is possible because mucosal cholesterol synthesis is high in bile acid deficiency. ${ }^{47}$ Furthermore, reabsorption of mucosal cholesterol may also be markedly reduced. At the moment, the magnitude of mucosal cholesterol secretion, cholesterol malabsorption, and impaired biliary lipid secretion is not at all, or only partially, known in patients with chronic active hepatitis and primary biliary cirrhosis. In conclusion, the present findings indicate that mild disturbances in parenchymal liver function cause infrequently major changes in cholesterol metabolism. However, abnormalities in secretory liver function are often associated with changes in cholesterol metabolism, especially in patients with orcein-positive hepatocellular deposits.

\section{References}

'Vlachevic ZR, Buhac I, Bell CC Jr, Swell L. Abnormal metabolism of secondary bile acids in patients with cirrhosis. Gut 1970; 11: 420-2.

${ }^{2}$ Turnberg LA, Grahame G. Bile salt secretion in cirrhosis of the liver. Gut 1970; 11: 126-33.

${ }^{3}$ Roovers J, Evrard E, Vanderhaeghe H. An improved method for measuring human bile acids. Clin Chim Acta 1968; 19: 449-57.

${ }^{4}$ Murphy GM, Ross A, Billing HB. Serum bile acids in primary biliary cirrhosis. Gut 1972; 13: 201-6.

${ }^{5}$ Bloomer JR, Allen MR, Klatskin G. Serum bile acids in primary biliary cirrhosis. Arch Intern Med 1976; 136: 57-61.

${ }^{6}$ Vlahcevic ZR, Miller JR, Farrar JT, Swell L. Kinetics and pool size of primary bile acids in man. Gastroenterology 1971; 61: 85-90.

${ }^{7}$ Vlahcevic ZR, Juttijudata P, Bell CC, Swell L. Bile acid metabolism in patients with cirrhosis. II Cholic and chenodeoxycholic acid metabolism. Gastroenterology 1972; 62: 1174-81.

${ }^{8}$ Blum M, Spritz N. The metabolism of intravenously injected isotopic cholic acid in Laennec's cirrhosis. J Clin Invest 1966; 45: 187-93.

${ }^{9}$ Kaye MD, Struthers JE, Tidball JS, De Niro E, Kern F. Factors affecting plasma clearance of ${ }^{14} \mathrm{C}$ cholic acid in patients with cirrhosis. Clin Sci Mol Med 1973; 45: 147-61. ${ }^{10}$ Vlahcevic ZR, Yoshida T, Juttijudata P, Bell CC Jr, Swell L. Bile acid metabolism in cirrhosis. III Biliary lipid 
secretion in patients with cirrhosis and its relevance to gallstone formation. Gastroenterology 1973; 64: 298-303.

${ }^{11}$ Miettinen TA, Siurala M. Micellar solubilization of intestinal lipids and sterols in gluten enteropathy and liver cirrhosis. Scand J Gastroenterol 1971; 6: 527-35.

${ }^{12}$ Miettinen TA. Lipid absorption, bile acids, and cholesterol metabolism in patients with chronic liver disease. Gut 1972; 13: 682-9.

${ }^{13}$ Salaspuro MP, Sipponen P. Demonstration of an intracellular copper-binding protein by orcein staining in longstanding cholestatic liver disease. Gut 1976; 17: 787-90.

${ }^{14}$ Salaspuro MP, Sipponen P, Makkonen H. The occurrence of orcein-positive hepatocellular material in various liver diseases. Scand J Gastroenterol 1976; 11: 677-81.

${ }^{15}$ Salaspuro MP, Sipponen P, Ikkala E, Kolho L, Makkonen HM, Miettinen TA, Räsänen JA, Siurala M. Clinical correlations and significance of orcein-positivity in chronic active hepatitis and primary biliary cirrhosis. Ann Clin Res 1976; 8: 206-15.

${ }^{16}$ Kesäniemi YA, Miettinen TA, Salaspuro MP, Sipponen $P$. Biliary bile acids in chronic active hepatitis and primary biliary cirrhosis. The significance of orcein positivity. Scand J Gastroenterol 1977; 12: suppl. 45: 45.

${ }^{17}$ Baggenstoss AH. Soloway RO, Summerskill WHJ, Elveback LR, Schoenfield LJ. Chronic active liver disease: The range of histologic lesions, their response to treatment and evolution. Human Pathol 1972; 3: 183-98.

${ }^{18}$ De Groote J, Desmet VJ, Gedigk P, Korb G, Popper H, Poulsen H, Scheuer PJ, Schmid M, Thaler H, Vehlinger $\mathrm{E}$, Wepler W. A classification of chronic hepatitis. Lancet 1968; 2: 626-8.

${ }^{19}$ Popper H, Schaffner F. Nonsuppurative destructive chronic cholangitis and chronic hepatitis. Prog Liver Dis 1970; 3: 336-54.

${ }^{20}$ Scheuer PJ. Primary biliary cirrhosis. Proc $R$ Soc Med 1967; 60: 1257-60.

${ }^{21}$ Sherlock S, Scheuer PJS. The presentation of 100 patients with primary biliary cirrhosis. $N$ Engl J Med 1973; 289: 674-8.

${ }^{22}$ Salaspuro MP, Laitinen OI, Lehtola J, Makkonen H, Räsänen JH, Sipponen P. Immunological parameters, viral antibodies and biochemical and histological findings in relatives of patients with chronic active hepatitis and primary biliary cirrhosis. Scand J Gastroenterol 1976; 11: 313-20.

${ }^{23}$ Davignon J, Simmonds WJ, Ahrens EH Jr. Usefulness of chromic oxide as an internal standard for balance studies in formula-fed patients and for assessment of colonic function. J Clin Invest 1968; 47: 127-38.

${ }^{24}$ Grundy SM, Ahrens EH Jr, Salen G. Dietary $\beta$-sitosterol as an internal standard to correct for cholesterol losses in sterol balance studies. J Lipid Res 1968; 9: 374-87.

${ }^{25}$ Doumas BT, Watson W, Giggs HG. Albumin standards and the measurement of serum albumin with bromcresol green. Clin Chim Acta 1971; 31: 87-96.

${ }^{26}$ Recommended methods for the determination of four enzymes in blood. Scand J Clin Lab Invest 1974; 33: 291-306.

${ }^{27}$ Owren A, Aas K. The control of dicumarol therapy and the quantitative determination of prothrombin and proconvertin. Scand J Clin Lab Invest 1951; 3: 201-8.

${ }^{28}$ Goldberg JA, Rutenburg AM. The colorimetric deter- mination of serum leusine aminopeptidase in urine and serum of normal subjects and patients with cancer and other diseases. Cancer 1959; 11: 283-91.

${ }^{29}$ Recommended method for the determination of gammaglutamyltransferase in blood. Scand J Clin Lab Invest 1976; 36: 119-25.

${ }^{30}$ Michaelsson M. Bilirubin determination in serum and urine. Scand J Clin Lab Invest 1961; 13: Suppl. 56, 1-80.

${ }^{31}$ Pearson S, Stern S, McGavack TH. A rapid, accurate method for the determination of total cholesterol in serum. Anal Chem 1953; 25: 813-7.

${ }^{32}$ Kessler G, Lederer H. Fluorometric measurement of triglycerides. In: Skeggs LT, ed. Automation in analytical chemistry. New York: Mediad, 1966: 341.

${ }^{33}$ Wheeler HO, Meltz JJ, Bradley SE. Biliary transport and hepatic storage of sulfobromophthalein sodium in unanesthetized dog, in normal man, and in patients with hepatic disease. J Clin Invest 1960; 39: 1131-43.

${ }^{34}$ Fausa $O$. Quantitative determination of serum bile acids using a purified $3-\beta$-hydroxysteroid dehydrogenase. Scand J Gastroenterol 1975; 10: 747-52.

${ }^{35}$ Van de Kamer JH, ten Bokkel Huining H, Weyers HA. Rapid method for the determination of fat in feces. $J$ Biol Chem 1949; 177: 347-55.

${ }^{36}$ Bolin DW, King RP, Klosterman EW. A simplified method for the determination of chromic oxide $\left(\mathrm{Cr}_{2} \mathrm{O}_{3}\right)$ when used as an index substance. Science 1952; 116: 634-5.

${ }^{37}$ Grundy SM, Ahrens EH Jr, Miettinen TA. Quantitative isolation and gas-liquid chromatographic analysis of total fecal bile acids. J Lipid Res 1965; 6: 397-410.

${ }^{38}$ Miettinen TA, Ahrens EH Jr, Grundy SM. Quantitative isolation and gas-liquid chromatographic analysis of dietary and fecal neutral steroids. J Lipid Res 1965; 6: 411-24.

${ }^{39}$ Bartlett GR. Phosphorus assay in column chromatography. J Biol Chem 1959; 234: 466-8.

${ }^{40}$ Schwartz CC, Almond HR, Vlahcevic ZR, Swell L. Bile acid metabolism in cirrhosis. V Determination of biliary lipid secretion rates in patients with advanced cirrhosis. Gastroenterology 1979; 77: 1177-82.

${ }^{41}$ Bergmann K von, Mok Hy, Hardison WGM, Grundy SM. Cholesterol and bile acid metabolism in moderately advanced, stable cirrhosis of the liver. Gastroenterology 1979; 77: 1183-92.

${ }^{42}$ Raedsch R, Lauterburg B, Hoffman AF. Personal communication.

${ }^{43}$ Hoffman AF. A physicochemical approach to the intraluminal phase of fat absorption. Gastroenterology 1966; 50: 56-64.

${ }^{44}$ Morgan RGH, Borgström B. The mechanism of fat absorption in the bile fistula rat. $Q J$ Exp Physiol 1969; 54: 228-43.

${ }^{45}$ Siperstein MD, Chaikoff IL, Reinhardt WO. C ${ }^{14}$ cholesterol. V. Obligatory function of bile in intestinal absorption of cholesterol. J Biol Chem 1952; 198: 111-4.

${ }^{46} \mathrm{Hoffman}$ AF, Borgström B. The intraluminal phase of fat digestion in man: the lipid content of the micellar and oil phases of intestinal content obtained during fat digestion and absorption. J Clin Invest 1964; 43: 247-57.

${ }^{47}$ Dietschy JM, Gamel WG. Cholesterol synthesis in the intestine of man: Regional differences and control mechanisms. J Clin Invest 1971; 50: 872-80. 